


\section{Una metafísica de la existencia para el siglo XXI}

Mario Teodoro Ramírez Universidad Michoacana de San Nicolás de Hidalgo

Resumen

En este ensayo partimos de la pregunta que indaga sobre un pensamiento filosófico a la altura del nuevo siglo en que vivimos, es decir, alejado ya de las formulaciones típicas del siglo XX y, en cierta medida, de toda la historia de la filosofía. Se propone así, desde la problemática del sentido y el sinsentido, una filosofía centrada en la noción de 'existencia' (en todo su alcance) en cuanto verdad absoluta del pensamiento. Desde esta propuesta se cuestionan las posturas que han hablado de un retorno a lo religioso, y del giro teológico, abogando por un ateísmo crítico y positivo. También, se hace una valoración del contenido ateo de la figura de Cristo como vía para la superación interna de la conciencia religiosa. Todo lo anterior se expone a través del comentario a la obra del filósofo francés Jean-Luc Nancy y de algunos otros autores. A manera de conclusión, definimos en cinco puntos tanto las condiciones como de las tareas y compromisos básicos de una filosofía renovada acorde con nuestra época.

Palabras clave: sentido, existencia, Dios, Cristo, justicia, infinito, siglo XXI. 


\section{Abstract}

In this essay we begin from the question that inquires about a philosophical thought that is up to the new century in which we live, that is to say, far away from the typical formulations of the XX century and, in a way, from the whole history of philosophy. It is proposed then, from the problematic of sense and nonsense, a philosophy based on the notion of 'existence' (in all its reach) regarding an absolute truth of thought. Since this proposal we challenge the positions that have talked about a return to the religious (and of the theological turn) pleading for an atheism that is both critical and positive. Also, is made a valuation of the atheist content of the figure of Christ as a way to the internal overcoming of the religious consciousness. All of this is exposed by of the commentary of the works of the French philosopher Jean-Luc Nancy and some other authors. As a conclusion, we define in five points the conditions, tasks and basic commitments of a renewed philosophy in accordance with our new age.

Keywords: Meaning, Existence, God, Christ, Justice, Infinity, XXI century.

\section{Introducción: diagnóstico}

$\mathrm{C}^{\mathrm{l}}$ presente ensayo propone delinear las características y contenidos de un filosofar a la altura de este nuevo siglo. El indicador temporal quizá sea un mero artilugio cultural, pero igual que otros artilugios, acaba teniendo, gracias a nuestra forma de utilizarlo, una eficacia simbólica innegable. Todos sentimos que vivimos en una nueva época, en un nuevo tiempo. El siglo XX es cosa del pasado, estamos más allá de él y, también, de muchas cosas que estaban atrás de él. Tenemos la sensación, y en mucho es un hecho, de que las cosas han cambiado de un modo crucial. Algunas imágenes, usos y concepciones de apenas hace treinta años nos resultan hoy totalmente inaceptables, si no es que hasta incomprensibles. El cambio se ha dado, sobre todo, en el orden cultural, en el 
de la vida social, en el de las mentalidades, las creencias, las ideas, las formas de comprensión, etcétera; no ha sido -no ha sido todavía- un cambio en el plano de la vida material, es decir, en el de las relaciones económicas y las estructuras de poder (a nivel local y a nivel internacional). Claramente, la filosofía tiene que ver con todo esto. Por una parte, los cambios se han reflejado también al interior de la práctica filosófica señalándole nuevas formas, temas y problemas. Pero, sobre todo, la filosofía tiene la urgente tarea, creemos, de comprender e interpretar el carácter de estos cambios, de ofrecernos una visión general de ellos, una sistematización o precisión de lo que era antes y de lo que viene ahora, de lo viejo y de lo nuevo. ¿Le cabe cumplir esa tarea? La pregunta viene a colación porque parece ser que una de las modificaciones fundamentales del siglo pasado tiene que ver con la crisis de los meta-relatos (como se le decía a finales del siglo XX), es decir, la puesta en cuestión o el señalamiento de la imposibilidad de un discurso omniabarcante, capaz de darnos cuenta de la realidad en su totalidad o de sus detalles más relevantes. Uno de los síntomas de nuestro tiempo parece ser la fragmentariedad, la dispersión, inclusive un activo rehuir al orden, a la organización, así una práctica sistemática de la des-totalización. No obstante, ¿qué tan "sistemática" es esa práctica? Empiezan a aparecer las paradojas, ya conocidas por la filosofía desde tiempos antiguos, de toda postura extrema, relativista, agnóstica o irracional. Las cosas no parecen entonces tan simples.

Por otra parte, como trataremos de mostrar adelante, una crisis como la que describimos ¿̇no posee todavía una significación, incluso filosófica? En el caso extremo, la resistencia del mundo a la filosofía ¿no es todavía un síntoma que puede constatarse y comprenderse filosóficamente? Quizá nunca se halle mejor la filosofía que cuando tiene que pensar una época que se le resiste o parece ya no necesitar de ella. No se trata de ir muy rápido y de volver a insistir simplemente en la necesidad de la filosofía, del valor de 
su enseñanza, de la importancia de sus procedimientos, de la relevancia de la tradición que la constituye. Podemos estar de acuerdo con esto y seguir obrando así. Pero, el reto propiamente filosófico es más complejo y da más sentido. Una época que no necesita de la filosofía puede existir por dos razones: porque esa época está irremediablemente condenada -a la irreflexión, a la inconsciencia, a la imposibilidad de cualquier proyecto-, o bien, porque está ya afortunadamente salvada, porque ha logrado "realizar" la filosofía -el sueño del filósofo desde los antiguos-, es decir, ha convertido a la filosofía en forma de vida, en actitud, en praxis cotidiana. ¿Cuál es la condición de nuestra época? ¿La primera o la segunda? La dificultad para responder a esta pregunta resulta, al menos para los que nos dedicamos a ella, un aliciente. La filosofía tiene todavía una tarea por realizar -quizá es la misma que ha tenido en toda su larga vida: justificarse a sí misma, justificando a la vez el mundo al que pertenece. De esto queremos hablar en esta ocasión. ¿Cuál es el tipo de filosofía que el mundo de hoy requiere? ¿Cuáles son las líneas o vectores de un ejercicio consecuente del filosofar en nuestro tiempo? ¿Qué tan a fondo debemos ir en la reflexión sobre la "crisis" de nuestra época? ¿Cuál es, pues, al menos filosóficamente, la "novedad" de nuestro tiempo?

Trataremos de contestar estas preguntas de la mano del pensamiento y la obra de Jean-Luc Nancy, al menos de algunos de sus textos. Partimos del planteamiento radical que este filosofo hace sobre el problema crucial del sin sentido de nuestra época. Asumimos su idea clave de la equivalencia entre existencia y sentido. Desde esta perspectiva, es decir, desde la de un cuestionamiento radical por el sentido, criticamos el retorno a lo religioso que algunos han planteado, con un breve comentario sobre las relaciones entre la idea de infinito y justicia. También, re-interpretamos de forma no religiosa el significado del cristianismo ("la deconstrucción del cristianismo”, según Nancy). Concluimos, un poco más 
allá de él (o, quizá, un poco más acá), puntualizando algunos de los rasgos de un filosofar propio de nuestra época.

\section{Sentido y sinsentido}

Comenzamos con una cita de Jean-Luc Nancy, uno de los pensadores más originales y provocadores de cuantos haya, quien se ha tomado en serio la tarea de pensar y comprender, la cual es, ante todo, un ejercicio de valor, de valentía. La inteligencia de la comprensión nunca sería posible sin la fuerza de una existencia que la sostiene, puesto que ella, la existencia, no se sostiene en nada o se sostiene a sí misma. Dice Nancy:

En más de un aspecto el mundo del sentido finaliza hoy en lo inmundo y en el no-sentido. Está cargado de sufrimiento, de extravío y de revuelta. Todos los 'mensajes' están agotados desde allí de donde parecen provenir. Es entonces que surge más imperativa que nunca la exigencia de sentido, que no es otra cosa que la existencia en tanto que ella no 'tiene' sentido. Y esta exigencia por sí sola ya es el sentido, con toda su fuerza de insurrección (2003: 24).

¿Qué nos dice el pensador francés? En un primer momento, una verdad de Perogrullo que constatamos todos los días: la ausencia de sentido, el fin del mundo del sentido, la prevalencia del sinsentido. Una vida social y personal anonadada por una crisis de sentido y, todavía más, por una crisis del sentido como tal -es decir, según Nancy, y ésta es una distinción es fundamental-: una crisis del sentido del mundo o de nuestra vida, pero, todavía más, una crisis de la noción o la fórmula misma del "sentido", al menos de la manera en que se la ha concebido hasta ahora, esto es, como una cierto tipo de razón o idea que determina y orienta desde fuera lo que es el caso: el mundo, la realidad, la acción; es decir, el sen- 
tido como constituyendo un orden, una estructura, una respuesta, "algo" y no "nada".

He aquí la gravedad de nuestra situación y su originalidad. No se trata sólo de una crisis de sentido como muchas otras que ha habido, como el hecho de que nos encontremos sin orientaciones o pautas para el vivir. Se trata de la crisis de la idea misma de sentido. Estamos ante el fin o la muerte de todas las grandes significaciones y, más allá -como lo expone también Hans Ulrich Gumbrecht (cfr. Gumbrecht, 2005)-, ante la muerte o el fin del orden de la significación en cuanto tal, que busca siempre permear los datos y procesos del mundo y la realidad, ordenándolos hacia un telos, un ideal o una norma. Radicalizar la "crisis de sentido" hasta convertirla en una "crisis del sentido" es la novedad de nuestra época, es el reto a pensar para un pensamiento que quiere permanecer en lo abierto y no arredrarse ante lo que sale a su paso, y es, sobre todo, y esto es más bien una apuesta, es la posibilidad de una renovación radical, de una innovación extrema, probablemente la re-invención o la invención misma de la Existencia.

En general, encontramos hoy una pérdida de parámetros; la palabra paradigma se ha desgastado hasta perder su propia fuerza paradigmática. Dios se ha retirado de tal manera que hasta algunos ateos suspiran por él. Nadie cree ya en los grandes discursos o las grandes representaciones, nadie reverencia los conceptos puros ni las categorías enaltecidas, nadie se desvela por los principios, las leyes, las normas universales, los a priori, la trascendencia y los trascendentales. No hay tampoco autoridad, nadie obedece a nadie, al menos, nadie cree ya que exista una autoridad per se, justificada en algún tipo de razón o criterio incuestionable e indubitable. Ésta es la crisis de cual, en todo momento, en diversos aspectos y desde diversos ámbitos, se habla desde hace tiempo, quizá desde siempre, pero nunca de forma tan contundente como en nuestros días. Hoy, hasta los nihilistas están en crisis... 
En un segundo momento, Nancy irrumpe su descripción con un giro asombroso. "Sólo de la ausencia de sentido emerge una exigencia radical de sentido y ésta exigencia es el sentido mismo", dice. Media con una expresión enigmática, sorprendente: la exigencia de sentido es "la existencia en tanto que ella no 'tiene' sentido". Y éste es el punto de la propuesta que el pensador francés nos ofrece. No hay que lamentarse de la disolución del mundo del sentido porque esto significa dejar abierta la aparición del sinsentido de la existencia, que es la única fuente y la única verdad del sentido. Dice Nancy: "Un pensamiento de la ausencia del sentido como la única prenda de la presencia de lo existente" (2002: 33), y agrega en otra parte: "El fin del mundo del sentido abre la praxis del sentido del mundo" (2003b: 24). La existencia como tal, desarrolla y "es" el sentido mismo. La experiencia de nuestro tiempo -el nihilismo- es en realidad el reconocimiento, por fin, de la existencia sin más. La existencia ahí, simple, desnuda, abierta, sin sustento, sin razón ni fundamento. Es, así, y sólo así, que ella, la existencia, es el sentido. No hay nada más que buscar, ninguna obsesión que mantener. La respuesta estaba, está, ha estado ahí, desde siempre. Como la "carta robada" del cuento de Poe: de tan obvia y evidente no la habíamos visto y constatado. No hay que darle sentido a la existencia, hay que tomar el sentido que ella nos da, o, más bien, que ella es. De otra manera, y ésta es la dificultad para pensar este asunto, siempre recaemos en la dicotomía, en separar existencia y sentido para oponerlas, para excluirlas, para someter una a otra (normalmente: la existencia al sentido). Al asumir que el sentido es la existencia, dejamos de suponer una relación exterior y dejamos de concebir al sentido como razón o significación. Pensamos al sentido como la estructura misma de la existencia, como aquello que ella es y hace. No se trata ya de una representación, de una noción o una idea. Tampoco hay que decir (como hacía todavía la fenomenología) que el sentido está en la existencia, o bien, ubicán- 
dolo en algún lado o algún aspecto o proceso de ella, de los cuales podría ser extraído y convertido entonces en un cierto objeto mental o conceptual. El sentido no está ni es en la existencia, sino que es la existencia como tal. Pero, ¿qué es la existencia como tal?

A diferencia del existencialismo del siglo $\mathrm{XX}$, que identifica existencia con la del ser humano (el Dasein, el existente), el existencialismo de Nancy es post o ultra humanista: existencia es todo lo que comparece, lo que es por principio exterioridad, espacialidad, es lo que se "expone", es "exposición", por ende, ya es en principio "co-existencia", "co-ser" más que "ser con" (Cfr. Nancy, 2001). Existentes son los humanos, pero también los animales, las plantas, los astros, los movimientos, etc. Existencia es lo que se abre y aquello a lo que el pensamiento debe abrirse ante todo.

\section{Crítica del retorno teológico}

Frente a la crisis de sentido y la crisis del sentido, no se trata, entonces, frente a la crisis de sentido y la crisis del sentido de intentar algún retorno o restablecimiento: de alguna ideología persistente, de la metafísica y sus grandilocuentes sistemas o incluso de la teología o la religión. El giro teológico del que se está hablando recientemente en algunos ámbitos de la filosofía parece más un síntoma del nihilismo que una vía plausible de su efectiva superación. Ciertamente, no podemos pensar filosóficamente sin la idea de Dios, pero esto nos lleva a asumir y amar el pensamiento y a alejarnos de su negación o disminución. El retorno religioso no podría ser sino signo de claudicación. Por esto, clama Nancy, hoy "no nos resta ni culto, ni plegaria, sino el ejercicio estricto y severo, sobrio y sin embargo jubiloso, de eso que se llama pensamiento" (2008: 258). Es cierto, también, que estamos más allá de la ingenuidad ilustrada que creía factible superar la teología y extinguir la mentalidad religiosa. El ateísmo ilustrado se afirmaba de manera tan 
dogmática como la propia mentalidad religiosa; pero, sobre todo, como llegó a decir Merleau-Ponty, una postura que sólo ofrece una negación o una serie de negaciones no tiene mayor plausibilidad ni alcance. Sigue siempre dependiente de aquello que niega. Necesitamos buscar una forma positiva de pensar el ateísmo, una que no subraye simplemente la negación y se quede fijada en lo que niega, sino que pueda encontrar algún tipo de afirmación; es decir, alguna forma de sentido (o de sin sentido), capaz de superar el reduccionismo, el conformismo, el puro materialismo, que parecen ser una implicación inevitable del ateísmo. Por ende, necesitamos ir más allá del ateísmo.

No obstante, parece que estamos en un círculo vicioso o en un movimiento de vaivén que no se detiene. Nuestra urgencia de sentido empuja al restablecimiento teológico. "Sólo la idea de Dios parece ser la respuesta a una pregunta extrema por el sentido", a una condición de ausencia total de sentido y de requerimiento total de sentido. Pero, la idea de Dios, como ya lo señalaron en su momento los grandes críticos de la religión (Kant y Hegel de alguna manera, pero sobre todo Feuerbach, Marx, Nietzsche, Freud y Sartre), lleva a cabo inevitablemente una extracción, una absorción: sacar el sentido de la existencia, reducir ésta al sin-sentido y poner todo el sentido fuera del mundo. Ahora bien, la alternativa no puede ser simplemente un ateísmo que extrajera de Dios el sentido para re-colocarlo en el mundo con el fin de volver a darle un sentido a la vida y al mundo, porque inevitablemente este sentido - llámese la Naturaleza, el Hombre, el progreso, la Historia o la Razón- seguiría manteniendo la forma de la ajenidad, es decir, una forma secularizada y positivizada, pero, al fin, todavía tan cerrada, definitiva y abstracta como la idea de Dios: éste es el equívoco en que han caído las diversas posturas anti-teológicas o inmanentistas de la modernidad (humanistas, materialistas, positivistas, existencialistas, progresistas, etc.) Nuestro ateísmo no ha sido lo suficien- 
temente radical y la modernidad siguió utilizando, desinflada y subrepticiamente, las grandes suposiciones y mistificaciones de la religión. Quizá la única forma de ser un verdadero ateo es viendo y asumiendo el mundo y la existencia tal como los juzga -negativamente, desde su punto de vista- el creyente más convencido: como un campo de sinsentido, como un valle de lágrimas, como existencia puramente negativa, como el reino del pesimismo, la desesperanza y la desesperación. Éste sería el camino que habría que cruzar para arribar a una asunción de la existencia y para no volver a ninguna sustitución o remplazo secularizado de Dios o de su idea. Sólo podemos captar en toda su radicalidad el problema que plantea la pregunta por el sentido si asumimos sin cortapisas la constatación del sinsentido de la existencia o, más bien, de la irreductibilidad por principio de la existencia al sentido en tanto que concebido o significado.

Hay que decirlo en los límites en que podemos decirlo: la idea de Dios posee un carácter intrínsecamente contradictorio (ambivalente o anfibológico, como decía Kant) y no hay manera para una mente clarividente de poder mantenerla. Desde siempre se nos insiste en dos cosas a la vez: que Dios es lo absoluto y que Dios se aparece de alguna manera en lo relativo del mundo, que es, en cierta forma, relativo. Tendríamos que escoger una de las dos posturas. $\mathrm{O}$ es lo absoluto, pero entonces no tenemos acceso a él y nada podemos saber de él, o es relativo, pero entonces no es exactamente Dios, y su ser es tan problemático como el nuestro. No obstante, la creencia en Dios se mantiene tozudamente y sigue siendo causa de las visiones más mistificadoras que encontramos en la cultura y el pensamiento.

Más allá de cuestiones lógicas, el problema básico con la creencia en Dios es que ineludiblemente ella hace injusticia al mundo y a la existencia. Pues con Dios el sentido de la existencia se vacía totalmente, la existencia es vaciada a fin de que sólo tenga ser el 
infinito vacío de $\mathrm{Su}$ idea. Por el contrario, necesitamos un sentido que, ante todo, haga justicia a la existencia, es decir, que asuma la existencia como tal, y que asuma que es ella, y en sí misma, lo que contiene su sentido propio, el sentido. Esto es - hay que repetirlo, en contra de la consigna común de muchos humanismos-, que no se trata de que nosotros "demos sentido" a la existencia (la soberbia, grandiosa o modesta, del humano) sino de que la existencia nos dé sentido a nosotros. Que la atendamos, que nos abramos a ella, para recibir de ella el sentido (sentido que, como hemos dicho, conlleva necesariamente una dimensión de sinsentido). Esto es lo que significa hacer justicia a la existencia. Respetar, considerar, aguantar, sopesar, asumir, lo que hay. Amarlo. Pues si, como dice Nancy, "el mal es el odio a la existencia como tal" (1996: 145), entonces amar la existencia como tal lleva al bien, por lo tanto es el bien. No es extraño, desde este punto de vista, que las religiones hayan sido en muchas ocasiones aliadas del mal y hayan producido más mal que bien a la humanidad. Podemos revertir la famosa frase de Dostoievsky, "si Dios no existe, todo está permitido", por la más histórica y empíricamente cierta: "si Dios existe (o si existe la creencia en él), todo está permitido". "Dios está de nuestra parte" dice el sacerdote asesino de la película de Almódovar, La mala educación.

Ahora bien, ¿qué significa hacer justicia? Otra vez parafraseando a Nancy: significa dar a la existencia lo que se merece (Cf. 2010). Siendo ésta la definición misma de justicia: dar a alguien lo que se merece, lo que le corresponde. ¿Pero qué se merece alguien, qué le corresponde a María o a Pedro? ¿Una cosa, dos, una lista? ¿Hasta dónde podemos ubicar lo que alguien se merece? Si nos ceñimos a tales o cuales condiciones (es decir a una serie finita, contable) necesariamente seríamos injustos. Si a la existencia sólo le diéramos tal o cual cosa, le reconociéramos tal o cual cualidad o propiedad, ¿con qué derecho podríamos hacerlo, con qué derecho le negaría- 
mos muchas otras más? Seríamos injustos. La justicia es necesariamente infinita, como lo es la injusticia también. Nunca acabamos de ser justos y siempre podemos ser infinitamente injustos. Estar conscientes de esto, es decir, de que "ser justo, es dar a cada uno lo que ni siquiera sabemos que le debemos" (Nancy, 2008: 32) es la primera expresión del sentido de la justicia, del sentido como tal.

Hacer justicia, comprender, tener en cuenta el carácter infinito de la justicia (y de la injusticia): éste es el sentido de la existencia; ahora bien, ésta es la exigencia de sentido de la existencia: una exigencia de justicia, con la existencia como tal, con la existencia tal o cual, con los existentes tales o cuales. Es la exigencia de poder vivir, comer, trabajar, crear, amar, cantar, actuar, ser y estar. Existir. Poder reflejar el ser del universo. Es el llamado mudo a un logos verdaderamente comprometido con el mundo.

\section{Dios ha muerto}

Así pues, Dios ha muerto. Intentar revivirlo es volver a hacer injusticia a la existencia, es volver a eliminar de la existencia el sentido de la justicia. Por esto no aceptamos que la solución a nuestra crisis de sentido sea una re-mistificación, un retorno a lo religioso. Algo relevante del cristianismo y de su valor es que admite como uno de sus momentos clave la desmitificación: un Dios que muere (en la cruz) para salvar al mundo. Mientras no asumamos la muerte de Dios, la muerte de Cristo, seguiremos, por el contrario, pudriendo al mundo... Y esto no parece muy piadoso, que digamos.

Haber hecho de Cristo un nuevo Dios es la más grande traición cometida contra él. Quedarse adorándolo es como si al escapar de un incendio por una escalera nos quedáramos detenidos en ella, adorándola, en lugar de acabar de bajar y ponernos a salvo con los pies en la tierra. Sobre el ateísmo (que profeso, naturalmente), quiero recordar unas palabras de Deleuze que me encantan: 
"el mayor valor de las religiones consiste en la nobleza y el coraje de los ateísmos que inspiran” (2007: 326). Según Nancy, el ateísmo, e incluso el nihilismo, deben ser vistos como el mejor, el más congruente cumplimiento de la religión misma, en particular del cristianismo: de ahí, a la vez, la necesidad de valorarlo y de superarlo. "Sólo puede ser actual un ateísmo que contemple la realidad de su proveniencia cristiana", dice Nancy; como, a la vez, "Sólo puede ser actual un cristianismo que contemple la posibilidad de su negación" (Pareyson, Apud. Nancy, 2008: 233). Esto mantiene una cuestión abierta para el pensamiento. Estamos más allá de un ateísmo abstracto, insensible (jacobino), meramente opuesto a la religión; sin embargo, también evitamos volver sin más y acríticamente a una postura religiosa.

Esto es lo que significa para Nancy "deconstrucción”: no eliminar, no mantener, no superar, sino encontrar un núcleo de verdad o de sentido en aquello que se deconstruye, pero que no se encontraría sino por la propia operación de la deconstrucción. El punto es saber mantenernos en este doble movimiento: sólo el ateísmo revela la verdad del cristianismo (de la religión); no obstante, sólo el cristianismo (la religión) define los términos en que el ateísmo puede ser válido (o tener un sentido positivo, afirmativo, más allá de la pura negación). Es en estos nuevos parámetros en los que Nancy propone repensar el tema de la religión y de las relaciones entre cristianismo, ateísmo y filosofía.

Como sabemos, el carácter desmitificador del cristianismo remite a la manera como Cristo cuestionó y destruyó ritos, mitos, formalismos, fariseísmos de toda laya -la religión exterior, de que hablaba el joven Hegel (1978: 73ss.; vid. Nancy, 2005)-. De alguna forma, la radicalización de esta desmitificación (que la Iglesia no efectúa) lleva a la Ilustración (la anti-mistificadora por excelencia), la cual, empero, olvida el origen cristiano-religioso del movimiento que ella cumple (y en tanto que "olvida" vuelve a establecer 
una nueva mistificación: la de la razón abstracta y objetiva). El cumplimiento hermenéutico de la desmitificación, por el contrario, al recordar su origen cristiano, la entiende como un proceso de liberación de la comprensión y del corazón: fin de la Ley externa, arribo al mandato del amor: éste es el secreto de la desmitificación: realización, aplicación, cumplimiento. Lo que decía Marx de la filosofía, se puede decir también del cristianismo, de la religión (Marx también lo pensaba así): "no podéis superarla, sin realizarla" (Marx, 1958: 6). Por el contrario, mientras sigamos afirmando la verdad de una religión, así sea la más hermosa, seguiremos pudriendo al mundo.

Es cierto que necesitamos recuperar la fe. Pero la fe en este mundo y en ningún otro. Sin fe, el mundo cae sobre sí mismo, se desinfla; sin embargo, una fe alienada, la fe en lo supramundano, inutiliza el poder de creer. En la medida en que no son entes compactos y acabados, sino que están conformados por una dimensión de apertura e indeterminación, el pensamiento, los otros, la acción, la existencia, el arte, requieren de fe -la afirmación de la afirmación- para poder ofrecernos toda su fuerza y todo el alcance de su realidad. Sólo una fe posmetafísica (pos-teológica, posreligiosa y pos-cristiana) puede hacer justicia al acontecimiento de la encarnación, esto es, de Cristo, y, en general, al acontecimiento de la Existencia sin más. El mesías no va a llegar, ya vino, se quedó aquí, y su llamado también. Lo que hemos de tener en mente no es la manera como la idea de Dios opera el vaciamiento de la existencia y la desustancialización general del mundo, sino, todo lo contrario, esa extraña operación que Cristo efectúa bajo el nombre de kenosis: el auto-vaciamiento de su divinidad para entregarse al mundo, para ser en el mundo y para que el mundo sea.

Cito La Biblia

Filipenses 6-7. Jesucristo:

6 quien, siendo por naturaleza Dios, 
no consideró el ser igual a Dios como algo a qué aferrarse.

7 Por el contrario, se rebajó voluntariamente,

tomando la naturaleza[b] de *siervo

y haciéndose semejante a los seres *humanos.

Y en Filipenses 2, 8:

$8 \mathrm{Y}$ al manifestarse como hombre,

se humilló a sí mismo

y se hizo obediente hasta la muerte,

iy muerte de cruz!

La kenosis es el modo en que Cristo hace justicia al mundo. Aquí y ahora es el momento de la "salvación", es decir, cada aquí y cada ahora... El día del juicio que, como dice Agamben, es todos los días y ninguno (2006: 139ss.)

Cristo es el Dios que vino a morir en la tierra para que no necesitáramos más Dioses, para liberarnos de la creencia de Dios. ¿Qué iglesia cristiana podría condescender con este punto de vista? Ninguna, ciertamente, en general ninguna religión. Sólo hay algo que puede condescender con esta revelación: esa palabra mundana e infinitamente humana que llamamos precisamente filosofía.

\section{¿Qué nos resta filosóficamente, humanamente?}

Sobre la base del divagador pensamiento anterior, anotaría cinco hitos y horizontes de la filosofía de nuestra época, es decir, del tan jovial como pendenciero siglo que pasa ante nosotros. Son las novedades, no necesariamente inéditas, del pensar de nuestros días, algunas de sus puntas más llamativas y significativas. Todas enfiladas a la realización de esa tarea de invención del sentido en cuanto reinvención de la existencia a que hemos aludido. 
1. La filosofía de la a-filosofía. Retomo una expresión de Maurice Merleau-Ponty poco conocida: su idea, expresada sólo en algunas de sus notas de curso o de investigación, de que el sentido, el destino y la verdad de la filosofía no se encuentra en ella misma, en el circular eterno sobre sí misma, sino en la "a-filosofía" (1996: 275); es decir, en la atención hacia todo lo que no es filosofía, todo lo que ella no capta ni comprende de principio y que, sin embargo, contiene el impulso y la recompensa de su búsqueda: esto es, la existencia tal cual, en su callado despliegue, en su mudez inconmensurable. Pero también el mundo con toda su complejidad y diversidad, con toda su capacidad de huida permanente a toda determinación y control conceptual u organizativo. Y más: el campo de la acción y el encuentro interhumano, el mundo de la política, de la capacidad de vivir y actuar entre otros y con otros; la cuestión del otro y de lo Otro en general. La a-filosofía es todo de lo más excelso a lo más cotidiano (quizá es la indistinción al fin entre lo excelso y lo cotidiano). No más una filosofía positiva, una dictadora del sentido; no más la dictadura de la verdad y de las buenas formas, sino una filosofía en cierta medida trágica, que es testimonio, riesgo y reto de un pensamiento sumido en la existencia, sin otro sostén que su insistencia en interrogar y su compromiso con la comprensión. No hay soluciones ni recetas. Ninguna certeza más que la del afán de comprender. Esto es lo único que nos cabe: si todo el armamento atómico hiciera estallar al mundo, debería haber una mente filosófica capaz de comprender, quizá en un instante, la catástrofe final como tal. No todo se habría perdido entonces.

2. El cuerpo, constancia y referente del pensamiento. No pugnamos ya por una reflexión filosófica que invariablemente nos hace volver a un mundo de conciencia, de vida interior, de sustancia espiritual que aparta del mundo. Basta un pensamiento sobre la corpora- 
lidad, desde, con y hacia el cuerpo.1 Ésta es nuestra condición y nuestra verdad primigenia: precisa en concreto, difusa en todos sus alcances e implicaciones. Más que un materialismo (que nombra demasiado y demasiado rápido), requerimos un "corporalismo", un filosofar vuelto al cuerpo, el absoluto de nuestra existencia. Existente en co-existencia, el cuerpo es intrínsecamente muchos cuerpos, interrelacionados, conectados, no sólo entre sí, o no sólo entre cuerpos humanos, sino con todos los otros cuerpos del mundo, del cosmos. El cuerpo, pues, que nos arraiga en el existir y nos abre al mundo, siendo él mismo "lo primero abierto", el umbral del universo. Es nuestra realidad, y la asunción de esto tiene implicaciones múltiples. Vuelvo a Nancy: "No hay otra evidencia -clara y distinta como la quiere Descartes- que la del cuerpo. Los cuerpos son evidentes -de ahí que toda justeza y toda justicia comiencen y terminen con ellos. Los injusto es confundir, quebrantar, triturar, asfixiar cuerpos, volverlos indistintos (reunidos sobre un centro oscuro, apiñados hasta destruir el espacio entre ellos- hasta asesinar incluso el espacio de su justa muerte)" (2003: 39). Al pensar desde el cuerpo, el pensamiento tiene que asumir, sin arredrarse, que le corresponde pensar el bien tanto como el mal, la salud y la enfermedad, la infelicidad y la felicidad, experiencias vivas, incomparable e irreductibles, de nuestro cuerpo, del ser cuerpo.

3. La diferencia de los sexos. El reconocimiento del cuerpo como la condición y verdad de nuestra existencia implica reconocer el carácter sexual y sexuado de nuestro cuerpo, reconocer la diferencia sexual que lo constituye y la manera como esta diferencia,

1 Maurice Merleau-Ponty es el filósofo de la corporalidad por excelencia. Ninguno como él ha profundizado en el ser y la contextura única del cuerpo. Vid. Fenomenología de la percepción (1977) y, para una ampliación metafísica de los alcances de su perspectiva, Lo visible y lo invisible (1970). También puede ser útil nuestro texto: La filosofía del quiasmo. Introducción al pensamiento de Maurice Merleau-Ponty (2013). 
en cuanto diferencia de los sexos, se hace y se piensa históricamente, tal como propone la filósofa feminista Geneviève Fraisse (Cf. Fraisse, 1996). La emergencia y desarrollo del feminismo, y el despliegue en nuestra época de la filosofía feminista, así como la masiva incorporación de las mujeres a la cultura y en particular a la discusión filosófica, constituyen un acontecimiento verdaderamente trascendental de nuestra época. Anuncian un cambio radical de nuestras concepciones, estilos, preocupaciones y formas de pensar. No sabemos lo que puede un cuerpo, decía Spinoza. No sabemos lo que puede un cuerpo femenino, podemos decir ahora. Un verdadero novus para la filosofía. Claramente, y más allá de las tareas pendientes de la lucha feminista, se vislumbra en nuestro horizonte la necesidad de pensar y elaborar un nuevo concepto de la humanidad, concebida como un ser a dos, como un ser dual, cuya diferencia innegable -masculino/femenino- no imposibilita la comunicación, la comunión incluso, pero que tampoco la opera bajo una determinación o un orden preestablecido (siempre, necesariamente patriarcal y excluyente). De lo que debemos partir es de que la relación sexual, y la relación interhumana en general, es a la vez, como apunta Nancy en su pequeño texto El 'hay' de la relación sexual, una "no relación", una relación en la no relación, o donde la relación nunca es un cumplimiento positivo y efectivo, nunca se hace identificación, identidad (2003). La diferencia es primigenia, es lo primero. Y no es imposible pensar desde ella y hacia ella. Al contrario, esto se antoja como la tarea más vital y retadora del pensamiento y de la propia existencia humana. La filosofía de las mujeres, el filosofar desde la diferencia, abre la vía de una reinvención de la existencia, de una reinvención de la humanidad toda. Como anunció hace tiempo nuestra colega Rubí de María Gómez Campos: el feminismo abre la vía de un nuevo humanismo, de un nuevo y creador modo de ser mujeres y hombres (2014). Éste será un humanismo verdaderamente arraigado al mundo, el cual tiene 
más visos de interrogación permanente y de búsqueda creadora que de ideología abstracta o de estrategia de dominación.

4. La "horizontalidad" del mundo interhumano, la horizontalidad del mismo mundo, lo que el feminismo ha vuelto plenamente evidente. Toda autoridad, toda solidez se desvanece en el aire. La democracia es hoy un exceso sobre los parámetros y todas las estructuras de un pretendido control. Es más una experiencia y una acción de creatividad y apertura que un orden normativo, constreńido y constrictor. Es la práctica de una vida que asume sin resquemor el fin de las trascendencias, el agotamiento del Sentido, la muerte de las jerarquías, el desmontaje de cualquier autoridad, legitimada per se. En el saber, en la cultura, en la política, en la vida cotidiana no reconocemos ya ninguna autoridad en cuanto principio imprescindible y constituyente, esto es, necesario a priori. Nadie cree ya en las vidas santas, sólidas, únicas, pétreas. Reconocemos la singularidad por todos lados, como referente de lo real, como nudo verdadero de lo existente. La crítica no para en ningún lado, no se detiene ante nada y ante nadie. Nada de privilegios, nada de salvoconductos en la existencia. Las monarquías, los reyes, las reinas o las princesas pertenecen ya al reino de la vulgaridad contumaz. Ninguna jerarquía se mantiene, ningún principio de analogía o de equivocidad ontológica. El Ser se dice de la misma manera, en el mismo grado y con el mismo alcance, de todo lo que es. La Ontología, esa extraña y a veces vilipendiada modalidad del pensamiento filosófico, encuentra en la democracia radical el espacio donde por fin su búsqueda adquiere sentido y verdad plenos. Como dice magistralmente Giorgio Agamben, el ser cualsea, el ser sin ninguna determinación ni cualificación, no es el ser "no importa cuál", sino el ser que siendo tal o cual, importa (2006: 11). La democracia total, la igualdad radical, la diversidad sin término es el punto de llegada de una Ontología verdaderamente consistente. 
Hoy todo importa. No hay un todo que importe más que cada singularidad en su inextricable y singular consistencia.

5. Mundialidad y mundialización del filosofar. Nancy ha reflexionado magistralmente sobre la significación filosófica de los fenómenos y los conceptos de globalización y mundialización, contraponiendo el segundo al primero, o quizá, mejor, llevando el primero, por medio del segundo, a derivaciones y consecuencias que lo transmutan, que lo cambian en una cosa distinta de lo que era, o si no, que producen al menos, más allá de él, una trasmutación de los procesos y significados de la realidad. El pensador francés contrapone la idea de "mundialización" a la de "globalización". Remite el significado de la segunda a lo que comúnmente se entiende: los procesos de integración capitalista y técnica multinacionales, la extensión generalizada de la lógica del mercado, con todo lo que ella implica y conlleva: la imposición de la abstracción mercantil, la generalización del principio de la equivalencia abstracta y la producción y legitimación de una injusticia global y total. Ahora bien, según Nancy, siguiendo a Marx, la globalización puede conducir a la mundialización, esto es, a una asunción de la mundanidad, del ser del mundo como y en cuanto tal, en cuanto implosión de todo sentido que viniera de fuera a determinarlo, a decirlo, en cuanto renuncia a todo fundamento, principio o razón, extra-mundano, que pretendiera justificar o guiar al mundo, dar su orden y su telos. Mundanidad significa el reconocimiento de que el mundo es aquello que se atiene a sí mismo en su existencia. Podemos decir que la mundanidad es la resistencia del mundo a ser mundo, es decir, un todo ordenado y conformado, pues como hemos dicho, todo orden y todo principio de conformación abjuran finalmente del ser del mundo. Un mundo es, más bien, como dice Nancy una "totalidad de remisiones, pero él mismo no remite a nada” (2010a: 22). De lo que se trata, más allá de la lógica de la globalización, es de crear, de generalizar el acto creador para en- 
frentar esa lógica y para transmutarla en una lógica (o una ilógica) de goce y afirmación de la existencia. Es la creación, en el arte y en todas las esferas de la cultura, incluida la filosofía, lo que puede venir a romper el orden de la significación y de las estructuras de poder y dominación. En esencia, de lo que se trata en la creación es de crear el mundo, o de crear mundo. Dice Nancy: "Crear el mundo quiere decir inmediatamente, sin retraso, volver a abrir cada lucha posible por un mundo, es decir, por aquello que debe dar lugar a lo contrario de un globalidad de injusticia sobre un fondo de equivalencia general. Pero conducir esta lucha, precisamente, en nombre de la evidencia de que este mundo procede de nada, de que es sin algo previo y sin modelo, sin principio y sin fin dados, $y$ de que es exactamente esto lo que hace a la justicia y el sentido de un mundo" (2003c: 54).

Creemos en esta tarea de creación del mundo la filosofía, la cual tiene también una tarea ineludible y novedosa: la de empezar a construir, por fin, un pensamiento verdaderamente universal, "mundial", no circunscrito ya a determinadas esferas geográficas o culturales, no limitado a una autojustificación etnocéntrica de su valor y su verdad. Por nuestra parte, no podemos sino considerar como una afrenta a la dignidad humano-universal la suposición de que la filosofía tiene una identidad o una pertenencia cultural; es decir, que ella es propia, y sólo es propia, de determinados pueblos y culturas, que sólo Europa es, como argumentaba Husserl (y como muchos otros siguen asumiéndolo), el nombre de un valor y un proyecto histórico-espiritual, así como las demás culturas o regiones -Oriente, "China e India”, Medio Oriente, África, América- que son sólo realidades "empíricas" o "histórico-contingentes" (Cfr. Husserl, 1973: 135ss.) Ese etnocentrismo es insostenible ya que imposibilita el supuesto valor de Europa: la racionalidad. Ésta no puede realizarse sin la comprensión de lo "Otro" - de lo supuestamente "no racional" o "irracional". Es el racionalismo unilateral, 
monológico, colonial y colonizador lo que nuestro tiempo ha destronado, parece que definitivamente. Lo que explota hoy por todos lados es una racionalidad filosófica multilateral y dialógica, incierta de sí pero inconmensurablemente abierta. Como lo expresa Nancy con estas enigmáticas palabras: "Es necesario, en definitiva, que la infinita razón que da razón de sí deje adivinar la sin-razón en acto (o la existencia efectiva), o bien, que se liquide a sí misma en su proceso desastrosamente interminable" (2003c: 27).

Lejos de morir o desaparecer la filosofía se encuentra, de hecho, más viva y extendida que nunca. Existe una verdadera explosión de actividad filosófica en Oriente, en China y Japón, en la India, en África y, claramente, en los países latinoamericanos. En Brasil, por ejemplo, donde hay una concurrencia casi masiva a las cátedras de filosofía que ofrecen las universidades públicas.

Con las existencias en el colmo de su ser concreto, con la apertura como carácter de la existencia y del cuerpo, mujeres y hombres, hombres y mujeres, en el diálogo infinito de la creatividad, con todo esto, tenemos para un filosofar sin fin sobre el planeta. Queremos el infinito, pero lo queremos ya. Aquí y ahora. Hic et nunc. En esta infinita finitud que somos y de la que hoy nos alegramos ser sin desesperación, sin angustia, sin miedo... Para quitarnos el miedo, para eso sirve la filosofía.

\section{Bibliografía}

Agamben, Giorgio, 2006, La comunidad que viene, José Luis Villacana (trad.), Valencia, Pre-Textos.

,2006, El tiempo que resta. Comentario a la carta a los romanos, Antonio Piñero (trad.), Madrid, Trotta.

Deleuze, Gilles, 2007, Dos regimenes de locos. Textos y entrevistas (1975-1995), José Luis Pardo (trad.), Valencia, Pre-textos. 
Fraisse, Geneviève, 1996, La diferencia de los sexos, Buenos Aires, Manantial.

Gómez Campos, Rubí de María, 2014, El feminismo es un humanismo, Barcelona, Anthropos.

Gumbrecht, Hans Ulrich, 2005, Producción de presencia. Lo que el significado no puede transmitir, Aldo Mazzucchelli (trad.), México, Universidad Iberoamericana.

Hegel, G.W.F., 1978, "La positividad de la religión cristiana”, en Escritos de juventud, José M. Ripalda (trad.), México, FCE, pp. 73-162.

Husserl, Edmund, 1973, La filosofía como ciencia estricta, Buenos Aires, Nova.

Marx, C., 1958, "En torno a la crítica a la filosofía del derecho de Hegel", en Carlos Marx y Federico Engels, La sagrada familia y otros escritos filosóficos de la primera época, Wenceslao Roces (trad.), México, Grijalbo.

Merleau-Ponty, Maurice, 1970, Lo visible y lo invisible, José Escudé (trad.), Barcelona, Seix-Barral.

, 1977, Fenomenología de la percepción, Jem Cabanes (trad.), Barcelona, Península.

, 1996, Notes de cours. 1959-1961, París, Gallimard.

Nancy, Jean-Luc, 1996, La experiencia de la libertad, Patricio Peñalver (trad.), Barcelona, Paidós.

, 2001, La comunidad desobrada, Pablo Perera (trad.), Madrid, Arena.

, 2002, Un pensamiento finito, Juan Carlos Moreno Romo (trad.), Barcelona, Anthropos.

, 2003, Corpus, Patricio Bulnes( trad.), Madrid, Arena.

, 2003a, El 'hay' de la relación sexual, Cristina de Peretti y Francisco J. Vidarte (trads.), Madrid, Síntesis. 
, 2003b, El sentido del mundo, Jorge Manuel Casas (trad.), Buenos Aires, La Marca.

, 2003c, La creación del mundo o la mundialización, Pablo Perera (trad.), Barcelona, Paidós.

, 2005, Hegel. La inquietud de lo negativo, Juan Manuel Garrido (trad.), Madrid, Arena.

, 2008, La declosión (Deconstrucción del cristianismo, 1), Guadalupe Lucero (trad.), Buenos Aires, La Cebra.

, 2010, Justo imposible. Breve conferencia acerca de lo que es justo o injusto, Pilar Ballesta (trad.), Barcelona, Proteus. , 2010a, L'Adoration (Déconstruction du christianisme, 2), París, Galilée.

Ramírez, Mario Teodoro, 2013, La filosofía del quiasmo. Introducción al pensamiento de Maurice Merleau-Ponty, México, FCE.

Recibido: 13 de septiembre de 2014 Aceptado: 12 de noviembre de 2014 